\title{
Tetrameric Bacterial Sodium Channels: Characterization of Structure, Stability, and Drug Binding ${ }^{\dagger}$
}

\author{
Ghasem Nurani, Matthew Radford, ${ }^{\ddagger}$ Kalypso Charalambous, ${ }^{\ddagger}$ Andrias O. O’Reilly, ${ }^{\ddagger}$ Nora B. Cronin, \\ Sharmeen Haque, and B. A. Wallace*
}

Department of Crystallography, Birkbeck College, University of London, London WC1E 7HX, U.K.

Received April 11, 2008; Revised Manuscript Received June 3, 2008

\begin{abstract}
NaChBac from Bacillus halodurans is a bacterial homologue of mammalian voltage-gated sodium channels. It has been proposed that a $\mathrm{NaChBac}$ monomer corresponds to a single domain of the mammalian sodium channel and that, like potassium channels, four monomers form a tetrameric channel. However, to date, although $\mathrm{NaChBac}$ has been well-characterized for functional properties by electrophysiological measurements on protein expressed in tissue culture, little information about its structural properties exists because of the difficulties in expressing the protein in large quantities. In this study, we present studies on the overexpression of $\mathrm{NaChBac}$ in Escherichia coli, purification of the functional detergent-solubilized channel, its identification as a tetramer, and characterization of its secondary structure, drug binding, and thermal stability. These studies are correlated with a model produced for the protein and provide new insights into the structure-function relationships of this sodium channel.
\end{abstract}

Voltage-gated sodium channels are integral membrane proteins that selectively transport sodium ions across cellular membranes in response to changes in membrane potential. Their function in mammals underlies neuronal signaling, muscle contraction, and hormone secretion (1). The first bacterial voltage-gated sodium channel $(\mathrm{NaChBac})^{1}$ was identified from Bacillus halodurans (2), and a number of orthologs were subsequently identified, forming a superfamily (3). The function of voltage-gated sodium channels in bacteria is still a matter of debate; however, there is evidence that these channels are involved in processes such as motility, chemotaxis, and $\mathrm{pH}$ homeostasis (4).

The pore-forming $\alpha$-subunit of mammalian voltage-gated sodium channels consists of a single polypeptide of 24 transmembrane $\alpha$-helices arranged as a pseudotetramer of four homologous domains (designated DI-DIV), with each domain comprised of six transmembrane (6TM) helices (designated S1-S6). In contrast, $\mathrm{NaChBac}$ appears to consist of a single 6TM domain of 274 amino acids, and it has been proposed to form a functional unit as a tetramer (1), although to date there has been no direct structural evidence to demonstrate that. Its kinetics of activation, inactivation, and recovery from inactivation are 10-100 times slower than those of mammalian voltage-gated sodium channels, and

$\dagger$ This work was supported by grants from the BBSRC (project grant to B.A.W. and SPoRT program grant to the MPSI consortium, N. Issacs, Glasgow University, principal investigator), plus a joint project grant from the Wellcome Trust to B.A.W. and P. Bullough (Sheffield University, Sheffield, U.K.). M.R. was a BBSRC CASE student supported by GlaxoSmithKline.

* To whom correspondence should be addressed: Phone: 44-207631-6800. Fax: 44-207-631-6803. E-mail: b.wallace@mail.cryst.bbk ac.uk.

$¥$ These authors contributed equally to this work.

${ }^{1}$ Abbreviations: $\mathrm{NaChBac}$, bacterial sodium channel; $\mathrm{CD}$, circular dichroism; TM, transmembrane; SDS, sodium dodecyl sulfate; DDM, dodecyl maltoside. although $\mathrm{NaChBac}$ is sodium selective, its high degree of homology to calcium channels in the pore domain allows it to be converted into a calcium selective channel by three aspartic acid point mutations (5). In addition, $\mathrm{NaChBac}$ can be blocked by calcium channel blockers (2). Further functional studies of $\mathrm{NaChBac}$ combined with mutagenesis have identified important residues involved in channel activation (6-8) and inactivation (9). The identification of glycine 219 as a critical residue involved in channel activation has shed light on what may be a general mechanism for voltage-gated ion channel gating $(6)$.

Sodium channels, like other membrane proteins, are notoriously difficult to study in vitro due to their generally low natural abundance in vivo and the difficulties with overexpression, detergent solubilization, and purification in an active form. Previous structural studies on sodium channels have consequently tended to focus on channels from electric eels, in which they are naturally present in high abundance in electroplax tissue (10-12). To date, expression of $\mathrm{NaChBac}$ has been reported in only cell-based systems for electrophysiological studies, and for luminescence studies, which only require small amounts of protein (13).

Information about $\mathrm{NaChBac}$ is important for our understanding of structural and functional properties that are common to both bacterial and eukaryotic channels, not only because of their sequence homology but also because $\mathrm{NaChBac}$ shares functional features common to all three eukaryotic voltage-gated ion channel families (14). In this paper, we report on the successful expression and purification of milligram quantities of folded functional protein and have carried out a series of structural and functional biophysical characterizations, establishing its secondary structure, oligomeric state, drug binding, and thermal stability. 


\section{EXPERIMENTAL PROCEDURES}

Materials. The cDNA of NaChBac from B. halodurans was generously provided by D. Clapham of Harvard Medical School (Boston, MA). Escherichia coli lipids were purchased from Avanti Polar Lipids, while the detergent dodecyl maltoside (DDM) was obtained from Anatrace. Mibefradil dihydrochloride hydrate was from Sigma Aldrich, and sodium green dye was from Invitrogen.

Cloning. Full-length NaChBac cDNA (274 amino acids) was amplified by PCR using Pfu DNA polymerase (Stratagene) and two oligos: F, 5'-GCCATATGAAAATGGAAGCTAGACAG-3' with an NdeI site at the $5^{\prime}$ end; and R, 5'-CGGATCCTCATTATTTCGATTGTTTAAGC-3' with two stop codons followed by a BamHI site at the $5^{\prime}$ end. The PCR product recovered from a $1 \%$ agarose gel was digested with NdeI and BamHI and inserted into a pET15b vector (Novagen) between NdeI and BamHI sites using T4 DNA ligase. The ligation mixture $(2 \mu \mathrm{L})$ was used for transformation into DH5 $\alpha$ cells. Once the transformation process was complete, the cells were spread on agar plates containing $100 \mu \mathrm{g} / \mathrm{mL}$ ampicillin and incubated at $37{ }^{\circ} \mathrm{C}$ overnight. Five colonies were picked from the plates, and DNA was prepared (pET15b/NaChBac). All colonies were confirmed by sequencing to contain a (His) ${ }_{6}$ tag followed by a thrombin digestion site at the N-terminus of the wildtype $\mathrm{NaChBac}$ gene.

Expression. Competent cells, the DE03 C41 strain of $E$. coli, were transformed by $\mathrm{pET} 15 \mathrm{~b} / \mathrm{NaChBac}$, and five colonies from the overnight agar plate were used to test induction. The colonies were grown in LB medium (Merck) with $100 \mu \mathrm{g} / \mathrm{mL}$ ampicillin (LB+AMP) at $37^{\circ} \mathrm{C}$ to an $\mathrm{OD}_{600}$ of 0.6. Cultures were cooled to $22{ }^{\circ} \mathrm{C}$, and isopropyl thiogalactoside (IPTG) (VWR International) was added to a final concentration of $0.2 \mathrm{mM}$. Cultures were incubated for $72 \mathrm{~h}$ at $22{ }^{\circ} \mathrm{C}$ while being shaken. Noninduced cultures treated in the same manner were also included for later comparison.

Cell cultures $(100 \mu \mathrm{L})$ were spun down at $16000 \mathrm{~g}$ for 10 min; the LB medium was removed, and the cells were disrupted by $2 \times$ lithium dodecyl sulfate buffer $(2 \times$ LDS buffer, Invitrogen), including reducing agent. After the samples had been heated at $70^{\circ} \mathrm{C}$ for $10 \mathrm{~min}, 10 \mu \mathrm{L}$ of each was loaded on a SDS gel (precast 4 to $16 \%$ gradient gel, Invitrogen).

Purification of NaChBac. Two flasks each containing 500 $\mathrm{mL}$ of $\mathrm{LB}+\mathrm{AMP}$ were inoculated with $5 \mathrm{~mL}$ of overnight culture and the cells grown at $37^{\circ} \mathrm{C}$ for $3 \mathrm{~h}$. After cooling to $22{ }^{\circ} \mathrm{C}$ and being induced with IPTG, the cells were incubated for a further $72 \mathrm{~h}$. The cells were collected and resuspended in $50 \mathrm{mM}$ Tris $(\mathrm{pH} 7.7)$ and $500 \mathrm{mM} \mathrm{NaCl}$ (buffer A) and left at $-80{ }^{\circ} \mathrm{C}$ overnight. The cells were thawed at room temperature and sonicated on ice for $2 \times$ $10 \mathrm{~min}$ in the presence of DNAase I $(2 \mu \mathrm{g} / \mathrm{mL})$, lysozyme ( $2 \mathrm{mg} / \mathrm{mL}$ ), and $0.2 \mathrm{mM}$ PMSF (VWR International). Disrupted cells were centrifuged at $10000 \mathrm{~g}$ for $30 \mathrm{~min}$. The resulting pellet was discarded and the supernatant centrifuged at $250000 \mathrm{~g}$ for $2 \mathrm{~h}$. The pellet, which mainly contains membranes, was resuspended in $180 \mathrm{~mL}$ of buffer $\mathrm{A}$, and DDM was added to a final concentration of $1 \%$ and incubated overnight at $4{ }^{\circ} \mathrm{C}$. Insoluble materials were removed by highspeed centrifugation, and after $20 \mathrm{mM}$ imidazole was added, the supernatant was loaded on a $5 \mathrm{~mL}$ His Trap nickel column (GE Healthcare) that was equilibrated with buffer A having $20 \mathrm{mM}$ imidazole (and 1\% DDM), at a flow rate of $0.5 \mathrm{~mL} / \mathrm{min}$. After washing steps with buffer B [500 mM $\mathrm{NaCl}, 50 \mathrm{mM}$ Tris- $\mathrm{HCl}$ (pH 7.7), and 0.1\% DDM] containing imidazole (first with $50 \mathrm{mM}$ and then with $100 \mathrm{mM}$ ), $\mathrm{NaChBac}$ was eluted from the column with $500 \mathrm{mM}$ imidazole in buffer B.

Elution fractions were concentrated in a Amicon concentrator (100 kDa cutoff). Some impurities (proteins smaller than $\sim 100 \mathrm{kDa}$ ) passed through the concentrator during this step.

Samples $(2 \mathrm{~mL})$ of the concentrated material were loaded on the top of a gel filtration column (Superdex200, Bio-Rad) in buffer B at $4{ }^{\circ} \mathrm{C}$ and eluted at a rate of $0.5 \mathrm{~mL} / \mathrm{min}$. The purity of fractions was assayed by SDS gel electrophoresis, and the identity of the single dominant band was confirmed by mass spectroscopic analysis.

For Western blotting, fractions from the gel filtration column were run on a precast denaturing gel (NuPAGE 4 to $16 \%$ gradient, Invitrogen) and transferred to a polyvinyl difluoride (PVDF) membrane. Anti-His G/AP antibody (Invitrogen) was used as the primary antibody, and goat antimouse IgG AP conjugate (Novagen) was used as the secondary antibody. Immunoblotting signals were developed with BCIP/NBT FAST tablets (Sigma).

Blue Native Gel. To examine the oligomeric state of native $\mathrm{NaChBac}$ in solution, fractions from the gel filtration column were run on a 4 to $16 \%$ gradient Native PAGE Bis-Tris gel (Invitrogen) (with $1 \% \mathrm{DDM}$ ) at $4{ }^{\circ} \mathrm{C}$. NativeMarker Unstained Protein Standards, 20-1230 kDa (Invitrogen), were used. To dissociate the oligomers, some $\mathrm{NaChBac}$ samples were treated with $1 \%$ SDS prior to being applied to the gel.

Dynamic Light Scattering. Dynamic light scattering recordings were made using a DynaPro-801 instrument. The change in diffusion coefficient as a function of protein concentration was measured, and extrapolation of the diffusion coefficient at "zero" concentration was used to calculate the sample molecular mass, using a standard curve of known diffusion coefficients and molecular masses. Initial protein concentrations of approximately $2 \mathrm{mg} / \mathrm{mL}$ were used, and for subsequent measurements, a series of three 1:1 dilutions were made using phosphate-buffered saline containing $0.1 \%$ DDM. Measurements were analyzed in bimodal mode, and an average of at least 25 measurements was used at each concentration.

Circular Dichroism (CD) Spectroscopy. CD spectra were recorded using an Aviv 215 spectropolarimeter equipped with a detector acceptance angle of $>90^{\circ}$ (for membrane/scattering samples) that had been calibrated using camphorsulfonic acid for optical rotation and benzene vapor for wavelength. Spectra were collected at $0.2 \mathrm{~nm}$ intervals over the wavelength range from 280 to $185 \mathrm{~nm}$. Three scans were collected for each protein sample and its corresponding baseline (which contained buffer and $0.1 \%$ DDM) in the same $0.01 \mathrm{~cm}$ path length Suprasil cuvette. Measurements were only made down to wavelengths at which the instrument dynode voltage indicated that the intensity of the light reaching the detector was sufficient for accurate detection (15). Using the CDtools processing package (16), the averaged baseline spectra were subtracted from the corresponding averaged protein spectra, and the spectra were smoothed with a Savitsky-Golay filter. 
Spectra were analyzed for secondary structure using the Dichroweb server (17) with the SP175 reference data set (18) and the CDSSTR algorithm (19), using a mean residue weight value of 114.8 .

For thermal scans, measurements were made on samples in $\mathrm{DDM}(0.95 \mathrm{mg} / \mathrm{mL}$ protein $)$ at $222 \mathrm{~nm}$ using intervals of $2{ }^{\circ} \mathrm{C}$; an equilibration time of $5 \mathrm{~min}$ was used at each temperature point. For the samples containing mibefradil, a final drug concentration of $200 \mathrm{mM}$ was used.

Flux Assay. We prepared lipid vesicles by dissolving $E$. coli lipids in a 1:1 chloroform/methanol mixture and freezedrying them under vacuum. Lipids were then rehydrated to $20 \mathrm{mg} / \mathrm{mL}$ lipid in $1 \mathrm{~mL}$ of $20 \mathrm{mM}$ Tris (pH 7.5) containing $10 \mu \mathrm{M}$ sodium green dye (20). Liposomes with a diameter of $\sim 100 \mathrm{~nm}$ were formed by extrusion using a mini extruder (Avanti Polar Lipids) (21).

$\mathrm{NaChBac}$ reconstitution was achieved by rapid dilution of DDM-solubilized protein into liposomes, producing a final lipid:protein weight ratio of 100:1. Initially, $500 \mu \mathrm{L}$ of 20 $\mathrm{mg} / \mathrm{mL}$ liposomes was added to $100 \mu \mathrm{g}$ of $\mathrm{NaChBac}(3.4$ $\mathrm{mg} / \mathrm{mL}$ in $0.1 \%$ DDM) and sonicated for $10 \mathrm{~s}$. Subsequently, DDM was diluted to below its critical micelle concentration by a 10 -fold dilution of the sample with $5 \mathrm{~mL}$ of $20 \mathrm{mM}$ Tris buffer $(\mathrm{pH} 7.5)$ and continuous mixing at room temperature for $20 \mathrm{~min}$. Proteoliposomes were pelleted by centrifugation at $650000 \mathrm{~g}$ and $25{ }^{\circ} \mathrm{C}$ for $60 \mathrm{~min}$. Finally, proteoliposomes were resuspended in $1 \mathrm{~mL}$ of Tris buffer (pH 7.5).

Fluorescence flux experiments were carried out using a FluoroMax-3 spectrofluorometer (Horiba Jobin Yvon Ltd.) at $25{ }^{\circ} \mathrm{C}$. Uptake of sodium into proteoliposomes was initiated by a 33-fold dilution of liposomes containing $\mathrm{NaChBac}$ into $20 \mathrm{mM}$ Tris buffer $(\mathrm{pH}$ 7.5) containing 300 $\mathrm{mM}$ sodium chloride. Changes in sodium green fluorescence were monitored at $540 \mathrm{~nm}(1 \mathrm{~nm}$ bandwidth, excitation at $512 \mathrm{~nm}$ ) following a mixing time of $\sim 10 \mathrm{~s}$, after which the increase in fluorescence had stabilized. $\mathrm{NaChBac}$ activity was assayed both in the presence and in the absence of the channel blocker mibefradil (2). Mibefradil $(200 \mu \mathrm{M})$ was added to the proteoliposome sample and incubated for $5 \mathrm{~min}$ at room temperature prior to the fluorescence experiments. Following the same procedure that is described above, control experiments were carried out in the absence of protein (liposomes without $\mathrm{NaChBac}$ but still in the presence of DDM), in the presence of mibefradil without protein (to test its effect on leakage), and in the absence of sodium chloride by diluting proteoliposomes or liposomes into sodium-free buffer. Each experiment was repeated three times with the exception of the controls carried out in the presence of sodium chloride-free buffer, which were repeated twice. As a final test of the maximal fluorescence response, $\mathrm{NaChBac}-$ containing liposomes were also treated by incubating with $2 \% \mathrm{DDM}$ at room temperature for 10 minutes to break up the liposomes, and the response was recorded.

Molecular Modeling. A homology model of the NaChBac transmembrane regions was generated using the crystal structure of the chimeric Kv1.2-Kv2.1 potassium channel (22), as this structure offers a complete set of coordinates for the voltage sensor region. Although the choice of structural template differed, our sequence alignment (Figure 4a) closely matched that of Blanchet et al. $(8,23)$; TCOFFEE (24) was used to generate the sequence alignment,

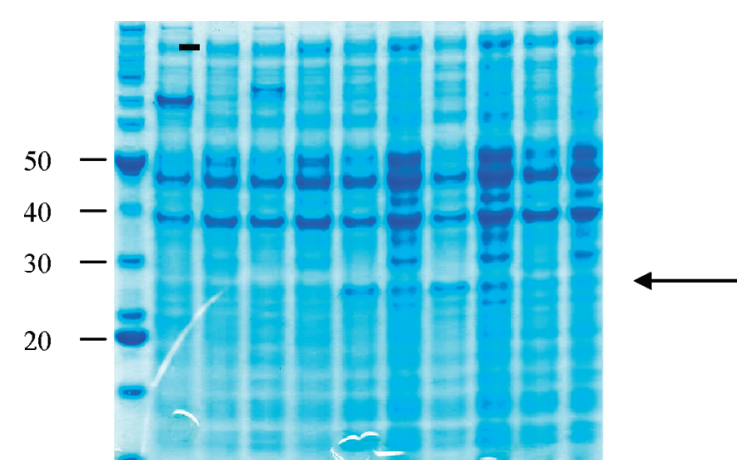

FIGURE 1: Expression of NaChBac, showing induction of protein in the presence of IPTG. Lane 1 contained molecular mass standards, and lanes $2-11$ contained five different colonies grown overnight at $37{ }^{\circ} \mathrm{C}$. Lanes $2,4,6,8$, and 10 contained $0.2 \mathrm{mM}$ IPTG, and lanes 3, 5, 7, 9, and 11 did not. The samples were solubilized in SDS buffer and loaded on a gradient SDS gel (4 to $12 \%$ ). The migration position of full-length $\mathrm{NaChBac}$ is indicated by the arrow. Lanes 6 and 8 show overexpression of NaChBac; the cells from lane 6 were used to produce the protein for purification.

with the first positive charge of the $\mathrm{NaChBac} \mathrm{S} 4$ helix aligned with the "R2" position of the potassium channel S4 helix. The accuracy of this alignment is supported by mutagenesis and functional studies on mutant $\mathrm{NaChBac}$ channels with substituted S4 charged residues (23).

Residues of the chimeric Kv1.2-Kv2.1 potassium channel structure (Protein Data Bank entry 2R9R) were mutated to the $\mathrm{NaChBac}$ sequence using the Biopolymer module of SYBYL (version 7.0, Tripos Inc., St. Louis, MO). The model was subjected to 500 rounds of conjugate-gradient minimization in SYBYL using the Tripos force field (25). The model figure was produced using PyMOL (DeLano Scientific, San Carlos, CA). The number of residues in helical conformations in the final model was identified using the DSSP algorithm (26). Prediction of the secondary structure for NaChBac regions not encompassed by the model (including the S5-S6 extracellular linker that forms the selectivity filter) was conducted according to the consensus of a number of secondary structure prediction algorithms (27).

\section{RESULTS}

Expression and Purification. Initial attempts to express $\mathrm{NaChBac}$ in E. coli were fraught with difficulties (28) and resulted in either cell death, inclusion bodies, or no expressed protein. To achieve successful overexpression in sufficient quantities for biophysical characterizations, a number of modifications were required, including change of plasmid, moving the (His) 6 tag from the $\mathrm{C}$-terminus to the $\mathrm{N}$-terminus, growth in complex medium, and growth at low temperatures. Eventually, conditions were found (as described in this paper) in which the induced expression level for $\mathrm{NaChBac}$ (Figure 1) was quite high relative to the level of expression of other membrane proteins in bacterial systems. Furthermore, under these conditions, the background (bacterial protein expression) was partially inhibited, which resulted in both a high yield and fewer impurities being present prior to purification. After a one-step purification on a nickel column, the yield was roughly $3 \mathrm{mg} / \mathrm{L}$ of culture and the impurities made up $<10 \%$, as evidenced by gel electrophoresis (Figure 2a). The identity of the main band was shown by mass spectrometry 


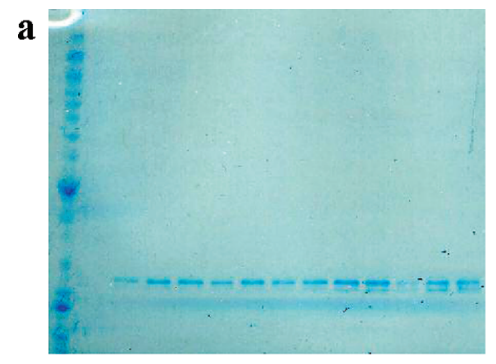

b
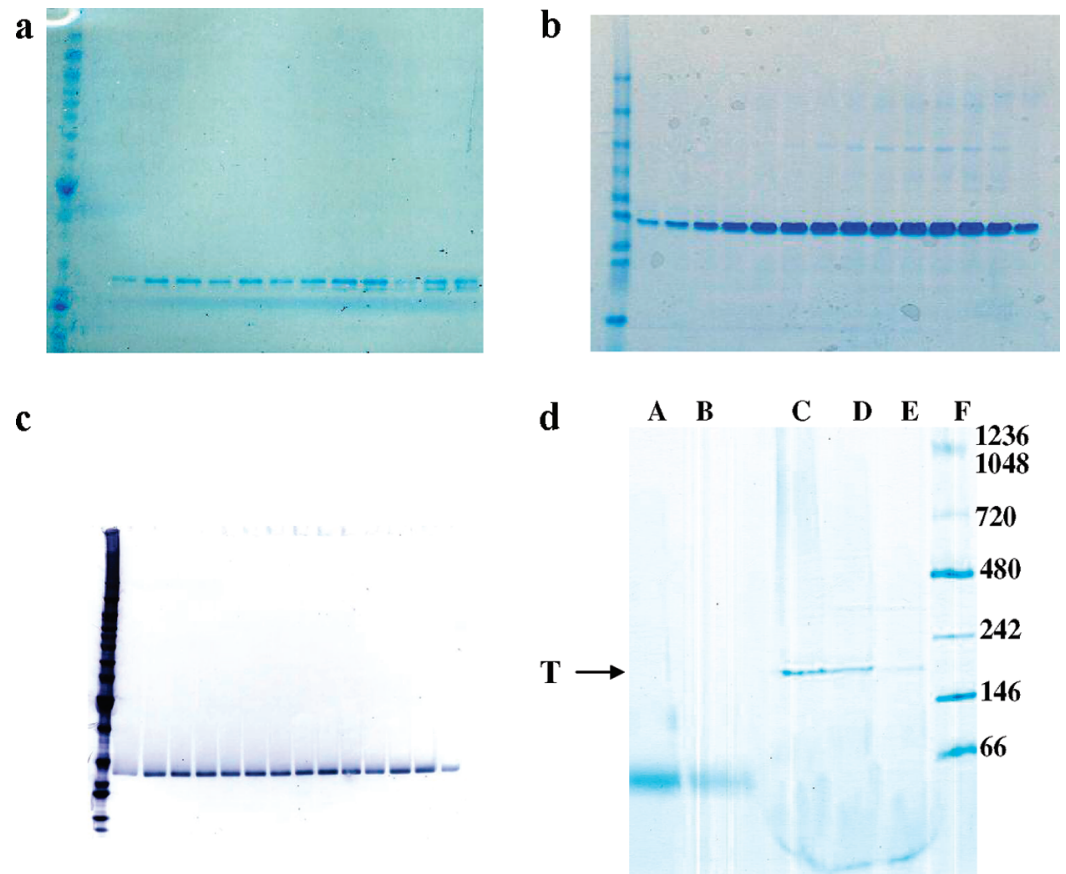

FIgure 2: Purification of NaChBac showing (a) elution from the Ni column, (b) elution from the gel filtration column, (c) Western blot of column fractions from the gel filtration column, and (d) Blue native gel characterization of the oligomerization state of NaChBac. In the latter, lanes A and B contained two dilutions of the protein treated with SDS to dissociate the oligomers (i.e., monomers); lanes $\mathrm{C}-\mathrm{E}$ contained dilutions of the protein in 1\% DDM (tetramers). Lane F contained molecular mass standards. The predicted position of a tetramer (T) is indicated by the arrow.

to be bona fide; the identity of the only other significant band (slightly lower molecular mass) was also shown to be derived from $\mathrm{NaChBac}$. It appeared to be a large $\mathrm{C}$-terminal fragment (consistent with it missing the $\mathrm{N}$-terminal end due to its lack of staining with antibodies against His tags on the Western blots) (data not shown). Because it was retained on the nickel column with the His-tagged proteins, we suggest it may have been a proteolyzed monomer (that was retained as part of tetrameric complex, in which at least one monomer had a His tag enabling it to be retained on the column). Using a concentrator having a $100 \mathrm{kDa}$ cutoff, impurities of less than $\sim 100 \mathrm{kDa}$ were effectively removed. Following a further purification step on a gel filtration column, intact $\mathrm{NaChBac}$ was seen to be effectively the only band that could be detected on a SDS gel (Figure 2b), and on Western blots (Figure 2c). The total yield of purified protein was $\sim 2 \mathrm{mg} / \mathrm{L}$ of culture. To examine the stability of the protein with time, a SDS gel and Western blot were obtained with the purified protein that had been maintained at $4{ }^{\circ} \mathrm{C}$ for 2 weeks. They were indistinguishable from those of the initial sample, exhibiting no detectable degradation products (data not shown).

Oligomeric State. To estimate the molecular mass and, therefore, the oligomeric state of the isolated protein in DDM, we ran a gel filtration column with the purified protein and found a single major peak. However, because the molecular mass calibration curve was made by running soluble standard proteins on the column, the estimated molecular mass was not expected to be highly accurate for a membrane protein that will have hydrodynamic properties different from those of soluble proteins. Nevertheless, the resulting molecular mass was estimated to be $\sim 227 \mathrm{kDa}$. Since a tetrameric $\mathrm{NaChBac}$ protein would be around $120 \mathrm{kDa}$ and the contribution from the detergent in the DDM micelles should be $\sim 80-100 \mathrm{kDa}$, it is reasonable to assume that the protein complex isolated is the tetrameric form of $\mathrm{NaChBac}$. Minor, later retained fractions corresponded to a molecular mass of $\sim 112 \mathrm{kDa}$, which would be compatible with a monomeric $\mathrm{NaChBac}(30 \mathrm{kDa})$ since the DDM micelles contribute 80-100 kDa.

Dynamic light scattering studies were also conducted to assess the molecular mass of the DDM-solubilized component. The sum of squares (SOS) fitting error which is defined as the sum of squares difference between the predicted and measured autocorrelation functions was consistently $<2$, indicating a good fit to the predicted autocorrelation function which consists of a single exponential. Large SOS values would indicate the experimental curve is multimodal and/or noisy. The measurements also showed that approximately $98 \%$ of the sample by mass was in a single state. The estimated molecular mass was $245 \mathrm{kDa}$, reasonably similar to the value obtained by gel filtration, again with some uncertainty due to the contribution of the detergent, but most consistent with a tetrameric complex with detergent.

To confirm the oligomeric nature, the DDM-solubilized material was run on a Blue native gel (Figure $2 \mathrm{~d}$ ). The protein migrated as a sharp peak with a total molecular mass of $\sim 220$ $\mathrm{kDa}$, again indicative of a tetrameric state of $\mathrm{NaChBac}$ in a mixed protein/detergent micelle and consistent with the gel filtration and dynamic light scattering results. The small amount of higher-molecular mass forms likely consists of aggregates that are common when membrane proteins are run on native gels. Finally, for comparison, the DDMsolubilized protein was treated with SDS (to dissociate it into monomers) prior to being run on a native gel (Figure 2d).

Secondary Structure and Thermal Stability. The CD spectrum of $\mathrm{NaChBac}$ in DDM (Figure 3a) is consistent with a protein that has a high helical content, having negative peaks at $\sim 222$ and $208 \mathrm{~nm}$ and a large positive peak at $\sim 195$ 

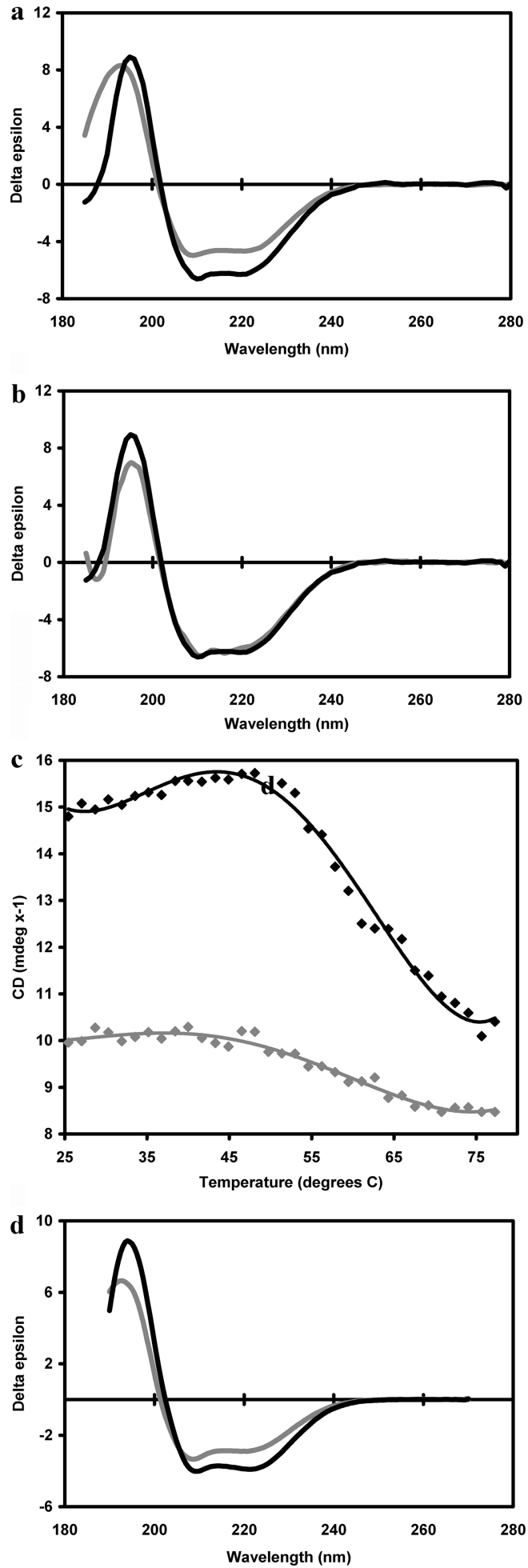

FIGURE 3: Circular dichroism spectra of NaChBac in DDM. (a) Comparison of CD spectra of $\mathrm{NaChBac}$ (black) and the sodium channel from El. electricus (gray) in DDM. (b) Comparison of the $\mathrm{CD}$ spectra of $\mathrm{NaChBac}$ in the presence (gray) and absence (black) of the channel-blocking ligand mibefradil. (c) Comparison of the thermal stabilities of $\mathrm{NaChBac}$ (black) and eel (gray) sodium channels, as shown by CD spectroscopy, monitored at $222 \mathrm{~nm}$. (d) Comparison of native folded tetrameric $\mathrm{NaChBac}$ (black) and SDSdissociated monomeric $\mathrm{NaChBac}$ (gray).

$\mathrm{nm}$. Its spectrum is similar in shape to that of the purified sodium channel isolated from Electrophorus electricus in DDM (Figure 3a), except that it has a slightly larger magnitude and a red-shifted positive peak, both indicating it has a higher overall helix content. This is consistent with the longer expected loops and termini of the eukaryotic protein, which, if partially nonhelical, would result in an overall lower percentage of helix. This similarity to eel protein in both DDM and genapol (11) detergents is heartening because the eel channels have been shown to be both properly folded and functional $(11 ; \mathrm{K}$. Charalambous et al., manuscript in preparation).

The secondary structure of $\mathrm{NaChBac}$, as determined from analyses of its CD spectra, is $67 \%$ helix, $8 \%$ sheet, and $25 \%$ other. The goodness-of-fit parameter (NRMSD) of 0.010 suggests that the calculated secondary structure corresponds well with the experimental data. This is consistent with the molecular model (Figure 4b) for the transmembrane domains of the protein: the helical sections of this model comprise $45 \%$ of the total residues. Additional helices predicted in the extramembranous regions (data not shown) would increase the total helix content to one similar to that calculated from the $\mathrm{CD}$ data, i.e., approximately $70 \%$. The calculated secondary structure of the eel channel from its CD spectrum was slightly lower (50\%) (11), which is again consistent with the relative appearances of its spectrum and the spectrum of $\mathrm{NaChBac}$, and with the observation that it has longer loops and termini that will have lower helical contents.

Upon addition of the channel-blocking drug mibefradil, the spectrum of $\mathrm{NaChBac}$ changes slightly, with a decrease in the magnitude of the $195 \mathrm{~nm}$ peak, but there is little change in the rest of the spectrum (Figure $3 b$ ). This might suggest that the drug not only binds to $\mathrm{NaChBac}$ in DDM micelles but also causes a small conformational change, resulting in a slight decrease in helix content.

The thermal stability of $\mathrm{NaChBac}$ in DDM was assessed using $\mathrm{CD}$ spectroscopy by monitoring the decrease in the magnitude of the peak at $222 \mathrm{~nm}$ (Figure 3c), which is associated primarily with helix content. The protein spectrum exhibited a characteristic cooperative two-state unfolding process, which was also as could be expected for a properly folded protein. Surprisingly, the protein appeared to be very stable, with an estimated $T_{\mathrm{m}}$ of $\sim 60^{\circ} \mathrm{C}$. This was similar to the $T_{\mathrm{m}}$ for the eel channel in the same detergent (Figure 3c). Interestingly, however, the total loss of helix content appears to be larger for the $\mathrm{NaChBac}$ protein. Even after "unfolding", both proteins retained a significantly helical structure. In addition, the presence of mibefradil during unfolding (data not shown) increased the stability of the $\mathrm{NaChBac}$ protein even further, which is often the case when ligands bind to proteins in their active conformations.

Finally, the CD spectra of $\mathrm{NaChBac}$ in DDM (where it is a tetramer) and in SDS (where the tetramer dissociates into a monomer) were compared (Figure 3d). The monomer, like the thermally unfolded protein, still retains a significant helical structure, again suggesting the secondary structure of this protein is significantly stable but also that the association into tetramers results in secondary structural changes that make the protein functionally competent.

Flux Activity. To demonstrate that the tetrameric protein is functional, a flux assay in the presence and absence of the channel blocker mibefradil was undertaken. The assay is based on quantitation of the increase in the fluorescence of the dye sodium green in the presence of sodium. When sodium enters the vesicles containing the dye, the fluores- 
a $\mathrm{S} 1$

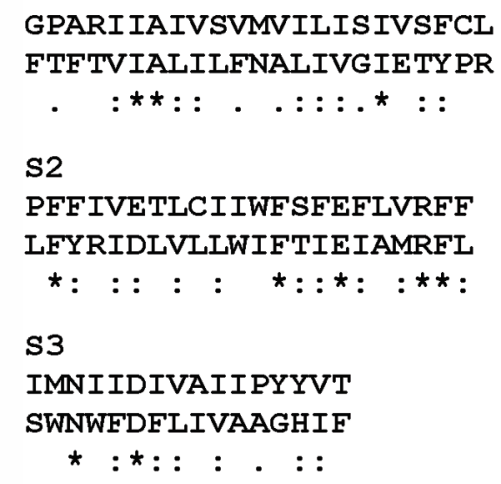

S4

RRVVQIFRIMRILRIFKLS

AQFVTVLRILRVLRVLRAI

$:$.* : :**:*:**:::

S4-S5

KGLQILGQTLK

PSLRRLVDALV

* : * : : *

S5

RELGLLIFFLFIGVILFSSAVYFAE

PALGNILILMS IFFY IFAVIGTMLF

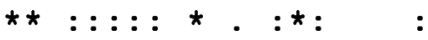

56

TIGGKIVGSLCAIAGVLTIALPVPVIVSNFN

VPWSWLYFVSFVLIGTFIIFNLFIGVIVNNV

. . : . : * : * . : : *

b

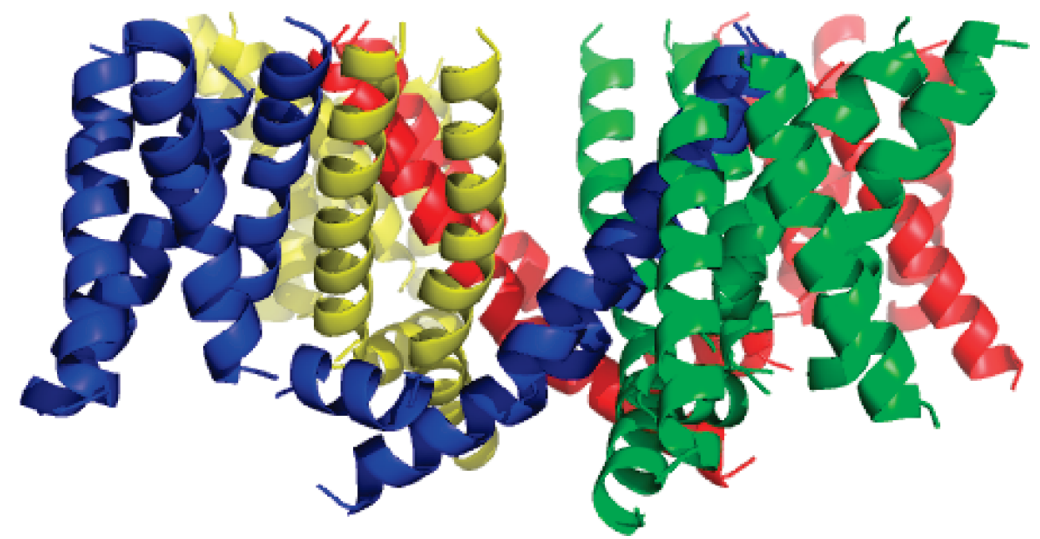

FIGURE 4: Homology model of NaChBac transmembrane segments. (a) Sequence alignment of the TM segments (designated S1-S6) of the Kv1.2-Kv2.1 chimera (top row) and $\mathrm{NaChBac}$ (middle row). The bottom row indicates identical residues (asterisk), conserved residues (colon), and semiconserved residues (period). (b) Side view (perpendicular to the membrane plane) of a ribbon depiction of the model of the TM regions showing the four monomers present in the tetramer in different colors.

cence increase can be monitored at $540 \mathrm{~nm}$. The control samples consisted of proteoliposome samples in which the added buffer did not contain sodium, and experienced only a very small increase $(<10 \%$ of the maximal increase observed following addition of sodium to proteoliposome samples). Liposomes alone (without protein) did experience an increase due to leakage, but this increase was significantly smaller than the increase in the proteoliposome samples which represented channel-induced flux (Figure 5). As a further control, proteoliposomes were treated with a channel blocker, mibefradil; the resulting fluorescence in those samples was not greatly different from that of the liposomes alone, suggesting that channel flux was indeed responsible for the increase in fluorescence, and that it could be prevented by blocking the channel. The presence of mibefradil itself (in liposomes without protein) did not significantly change the level of leakiness. As a final control, channels blocked by mibefradil but without sodium present exhibited fluorescence indistinguishable from that of the channels without sodium (and hence the change in fluorescence is not related to a spectroscopic property of the drug). The maximal level of the fluorescence response (for $\mathrm{NaChBac}$-containing liposomes that were subsequently dissolved in detergent) demonstrated a small but significant further increase, suggesting that not all the liposomes necessarily contained active 


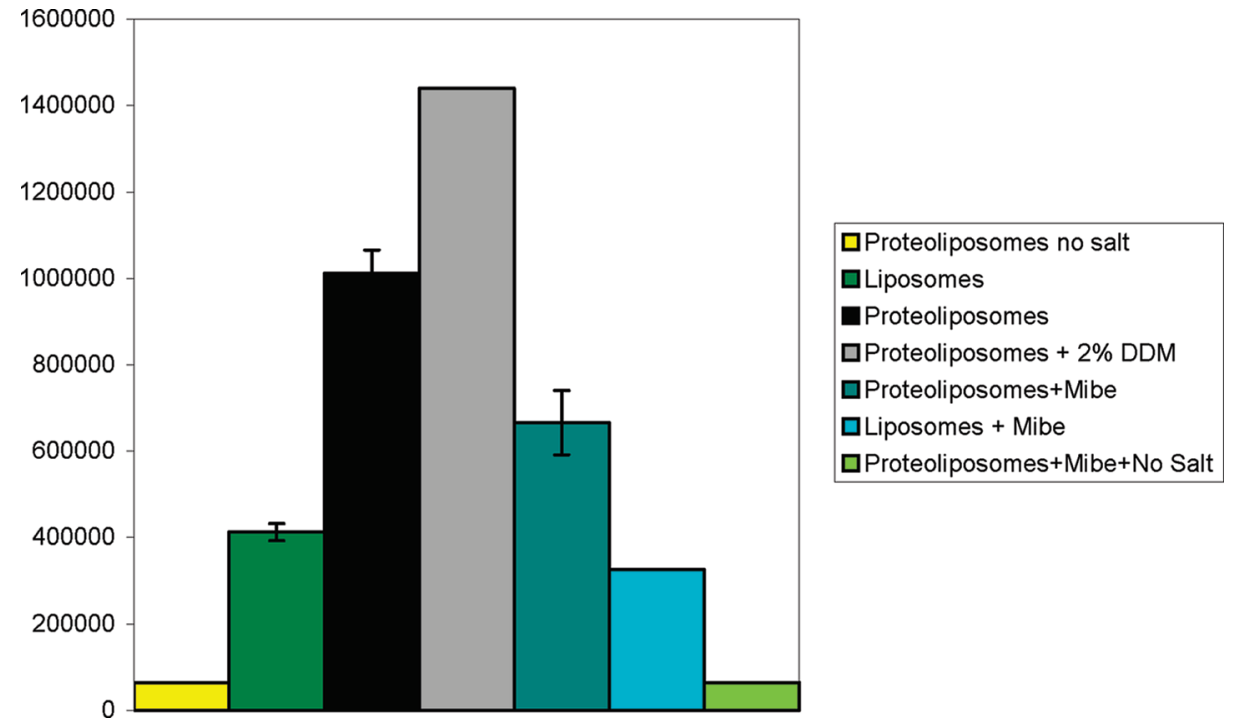

FIGURE 5: Changes in sodium green fluorescence at $540 \mathrm{~nm}$ following the rapid dilution of the samples (in order from left to right): proteoliposomes into sodium-free buffer, liposomes diluted with sodium buffer, proteoliposomes diluted with sodium buffer, proteoliposomes diluted with sodium buffer and treated with $2 \%$ DDM to determine the maximal fluorescent response, proteoliposomes preincubated with $200 \mu \mathrm{M}$ mibefradil (Mibe) and then diluted with sodium buffer, liposomes preincubated with $200 \mu \mathrm{M}$ mibefradil and then diluted with sodium buffer, and proteoliposomes preincubated with mibefradil and then diluted with sodium-free buffer. Error bars represent one standard deviation in the value of the repeated measurements.

protein, or that the proteins present were not all oriented in the same direction in the reconstituted liposomes.

These studies have thus demonstrated that the purified $\mathrm{NaChBac}$ protein can be successfully reconstituted into liposomes, producing functional channels that not only transport sodium but are also blocked by a known channel blocker.

\section{DISCUSSION}

The overexpression and purification of membrane proteins are much more challenging than those of soluble proteins $(29,30)$. In particular, overexpression of membrane proteins can often cause cell death, which was the case in many of our $\mathrm{NaChBac}$ expression trials. This may be due to interference with components of the membrane essential for normal cellular functions and the necessity for maintenance of the intracellular ion content. In addition, protein yields tend to be limited by the finite capacity of the cell membrane system, and the ability to fold properly into the host membrane. In addition to difficulties in expression, extraction of protein from the membrane in a functional state can also be problematic.

We have developed a method for overexpressing the bacterial sodium channel from B. halodurans in E. coli in a functional form that enabled a wide range of biochemical and biophysical characterizations of this protein to be carried out.

It had been proposed that the $\mathrm{NaChBac}$ channel would be composed of four monomers forming a tetrameric assembly, similar to that found in both bacterial and eukaryotic potassium channels, but unlike mammalian sodium channels, which are a single polypeptide chain forming a pseudotetramer of four homologous domains. This study has demonstrated for the first time that the functional oligomeric state of $\mathrm{NaChBac}$ is indeed a tetramer. Furthermore, CD spectroscopic studies have shown that the measured secondary structure is consistent with what is expected for a 6TM channel based on homology modeling.

The DDM-solubilized protein is not only folded and tetrameric but also capable of binding the channel blocker mibefradil, as shown by both the flux assay and the CD binding study. The protein shows considerable stability to both thermal denaturation and treatment with SDS, which dissociates the monomers, both of which result in some loss of helix content but retention of a largely helical polypeptide. Such stability of a membrane protein helical core is reminiscent of bacteriorhodopsin (31), which also remains mostly helical even after unfolding in SDS, and KcsA, which even retains its tetrameric structure in SDS (32). The resistance to thermal stress in the anisotropic environment of a detergent micelle may reflect its requirement for flexibility, enabling it to undergo significant conformational changes associated with state-dependent functional changes.

In conclusion, we have demonstrated we can isolate and purify an active sodium channel protein and have characterized its secondary and quaternary structures, its thermal stability, and its binding of the drug mebifradil.

\section{ACKNOWLEDGMENT}

We thank Dr. Len Packman at the Protein and Nucleic Acid Chemistry facility (PNAC), Department of Biochemistry, University of Cambridge, Cambridge, U.K., for the mass spectroscopic analyses, Dr. Tina Daviter of the Birkbeck/UCL Biophysics Laboratory for help with the fluorescence measurements, and Dr. Tim Dale of GlaxoSmithKline for helpful discussions.

\section{REFERENCES}

1. Hille, B. (2001) Ion channels of excitable membranes, Sinauer, Sunderland, MA.

2. Ren, D., Navarro, B., Xu, H., Yue, L., Shi, Q., and Clapham, D. E. (2001) A prokaryotic voltage-gated sodium channel. Science 294, 2372-2375. 
3. Koishi, R., Xu, H., Ren, D., Navarro, B., Spiller, B. W., Shi, Q. and Clapham, D. E. (2004) A superfamily of voltage-gated sodium channels in bacteria. J. Biol. Chem. 279, 9532-9538.

4. Ito, M., Xu, H., Guffanti, A. A., Wei, Y., Zvi, L., Clapham, D. E., and Krulwich, T. A. (2004) The voltage-gated Na_channel NaVBP has a role in motility, chemotaxis, and $\mathrm{pH}$ homeostasis of an alkaliphilic Bacillus. Proc. Natl. Acad. Sci. U.S.A. 101, 1056610571.

5. Yue, L., Navarro, B., Ren, D., Ramos, A., and Clapham, D. E. (2002) The cation selectivity filter of the bacterial sodium channel, NaChBac. J. Gen. Physiol. 120, 845-853.

6. Zhao, Y., Yarov-Yarovoy, V., Scheuer, T., and Catterall, W. A. (2004) A gating hinge in $\mathrm{Na}^{+}$channels: A molecular switch for electrical signaling. Neuron 41, 859-865.

7. Zhao, Y., Scheuer, T., and Catterall, W. A. (2004) Reversed voltage-dependent gating of a bacterial sodium channel with proline substitutions in the S6 transmembrane segment. Proc. Natl. Acad. Sci. U.S.A. 101, 17873-17878.

8. Blanchet, J., Pilote, S., and Chahine, M. (2007) Acidic residues on the voltage-sensor domain determine the activation of the NaChBac sodium channel. Biophys. J. 92, 3513-3523.

9. Pavlov, E., Bladen, C., Winkfein, R., Diao, C., Dhaliwal, P., and French, R. J. (2005) The pore, not cytoplasmic domains, underlies inactivation in a prokaryotic sodium channel. Biophys. J. 89, 232242.

10. Sato, C., Ueno, Y., Asai, K., Takahashi, K., Sato, M., Engel, A., and Fujiyoshi, Y. (2001) The voltage-sensitive sodium channel is a bell-shaped molecule with several cavities. Nature 409, 988 999.

11. Cronin, N. B., O'Reilly, A., Duclohier, H., and Wallace, B. A. (2003) Binding of the anticonvulsant drug lamotrigine and the neurotoxin batrachotoxin to voltage-gated sodium channels induces conformational changes associated with block and steady-state activation. J. Biol. Chem. 278, 10675-10682.

12. Cronin, N. B., O'Reilly, A., Duclohier, H., and Wallace, B. A. (2005) Effects of deglycosylation of sodium channels on their structure and function. Biochemistry 44, 441-449.

13. Richardson, J., Blunck, R., Ge, P., Selvin, P. R., Bezanilla, F., Papazian, D. M., and Correa, A. M. (2006) Distance measurements reveal a common topology of prokaryotic voltage-gated ion channels in the lipid bilayer. Proc. Natl. Acad. Sci. U.S.A. 103, $15865-15870$.

14. Hanlon, M., and Wallace, B. A. (2002) Structure and function of voltage dependent ion channel regulatory $\beta$ subunits. Biochemistry 41, 2886-2894.

15. Lees, J. G., Smith, B. R., Wien, F., Miles, A. J., and Wallace, B. A. (2004) CDtool: An integrated software package for circular dichroism spectroscopic data processing, analysis, and archiving. Anal. Biochem. 332, 285-289.

16. Miles, A. J., and Wallace, B. A. (2006) Synchrotron radiation circular dichroism spectroscopy of proteins and applications in structural and functional genomics. Chem. Soc. Rev. 35, 39-51.
17. Whitmore, L., and Wallace, B. A. (2004) DICHROWEB, an online server for protein secondary structure analyses from circular dichroism spectroscopic data. Nucleic Acids Res. 32, W668-W673.

18. Lees, J. G., Miles, A. J., Wien, F., and Wallace, B. A. (2006) A reference database for circular dichroism spectroscopy covering fold and secondary structure space. Bioinformatics 22, 1955-1962.

19. Sreerama, N., and Woody, R. (2000) Estimation of protein secondary structure from CD spectra: Comparison of CONTIN, SELCON and CDSSTR methods with an expanded reference set. Anal. Biochem. 282, 252-260.

20. Balmoos, C., and Dimroth, P. (2004) A continuous fluorescent method for measuring $\mathrm{Na}^{+}$transport. Anal. Biochem. 335, 334337.

21. Lentz, B. R., McIntyre, G. F., Parks, D. J., Yates, J. C., and Massenburg, D. (1992) Bilayer curvature and certain amphipaths promote poly(ethylene glycol)-induced fusion of dipalmitoylphosphatidylcholine unilamellar vesicles. Biochemistry 31, 2643-2653.

22. Long, S. B., Tao, X., Campbell, E. B., and MacKinnon, R. (2007) Atomic structure of a voltage-dependent $\mathrm{K}^{+}$channel in a lipid membrane-like environment. Nature 450, 376-382.

23. Blanchet, J., and Chahine, M. (2007) Accessibility of four arginine residues on the $\mathrm{S} 4$ segment of the Bacillus halodurans sodium channel. J. Membr. Biol. 215, 169-180.

24. Notredame, C., Higgins, D. G., and Heringa, J. (2000) T-Coffee: A novel method for fast and accurate multiple sequence alignment. J. Mol. Biol. 302, 205-217.

25. Clark, M., Cramer, R., and Van Opdenbosch, N. (1989) Validation of the general purpose Tripos 5.2 force field. J. Comput. Chem. $10,982-1012$.

26. Kabsch, W., and Sander, C. (1983) Dictionary of protein secondary structure: Pattern recognition of hydrogen-bonded and geometrical features. Biopolymers 22, 2577-2637.

27. Combet, C., Blanchet, C., Geourjon, C., and Deleage, G. (2000) NPS@: Network protein sequence analysis.Trends Biochem. Sci. $25,147-150$.

28. Haque, S. (2007) Molecular Biology of the Voltage-Gated Sodium Channel. Ph.D. Thesis, Birkbeck College, University of London, London.

29. Tate, C. G. (2001) Overexpression of mammalian integral membrane proteins for structural studies. FEBS Lett. 504, 94-98.

30. Seddon, A. M., Curnow, P., and Booth, P. J. (2004) Membrane proteins, lipids and detergents: Not just a soap opera. Biochim. Biophys. Acta 1666, 105-117.

31. Riley, M. L., Wallace, B. A., Flitsch, S. L., and Booth, P. J. (1997) Slow $\alpha$ helix formation during folding of a membrane protein. Biochemistry 36, 192-196.

32. Valiyaveetil, F. I., Zhou, Y., and MacKinnon, R. (2002) Lipids in the structure, folding, and function of the $\mathrm{KcsA} \mathrm{K}^{+}$channel. Biochemistry 41, 10771-10777.

BI800645W 